THE INTERNATIONAL

REVIEW OF RESEARCH IN

OPEN AND DISTANCE LEARNING

\title{
Beyond the Net Generation Debate: A Comparison of Digital Learners in Face-to-Face and Virtual Universities
}
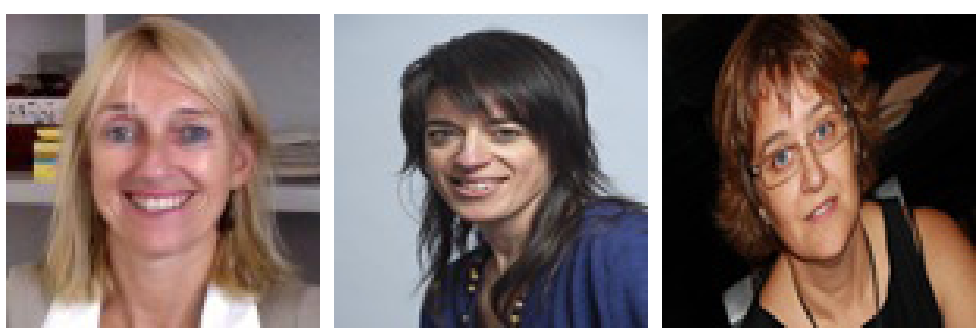

Begoña Gros and lolanda Garcia Universitat Oberta de Catalunya, Spain

Anna Escofet

Universitat de Barcelona, Spain

\section{Abstract}

In the last decade, an important debate has arisen about the characteristics of today's students due to their intensive experience as users of ICT. The main belief is that frequent use of technologies in everyday life implies that competent users are able to transfer their digital skills to learning activities. However, empirical studies developed in different countries reveal similar results suggesting that the "digital native" label does not provide evidence of a better use of technology to support learning. The debate has to go beyond the characteristics of the new generation and focus on the implications of being a learner in a digitalised world. This paper is based on the hypothesis that the use of technology to support learning is not related to whether a student belongs to the Net Generation, but that it is mainly influenced by the teaching model.

The study compares behaviour and preferences towards ICT use in two groups of university students: face-to-face students and online students. A questionnaire was applied to a sample of students from five universities with different characteristics (one offers online education and four offer face-to-face education with LMS teaching support). 
Findings suggest that although access to and use of ICT is widespread, the influence of teaching methodology is very decisive. For academic purposes, students seem to respond to the requirements of their courses, programmes, and universities. There is a clear relationship between students' perception of usefulness regarding certain ICT resources and their teachers' suggested uses of technologies. The most highly rated technologies correspond with those proposed by teachers. The study shows that the educational model (face-to-face or online) has a stronger influence on students' perception of usefulness regarding ICT support for learning than the fact of being a digital native.

Keywords: Net Generation, digital learner, students' characteristics, online learning, higher education

\section{Introduction}

Net Generation (Tapscott, 1998), digital natives (Prensky, 2001), and Millennial Learners (Oblinger \& Oblinger, 2005) are three of the most popular terms that have been used to refer to current students, born after 1982. Each author describes this new generation using a different term, but all of them share similar features. Their main hypothesis is that immersion in a technological context influences the skills and interests of the new generation in a considerable way. The most common characteristics attributed to members of this generation are that they make extensive use of technology for communication purposes and that this intensive use makes them experts in technology (Oblinger \& Oblinger, 2005; Prensky, 2001; Tapscott, 1998).

These ideas have become very controversial since the main part of the debate has not been informed empirically. Moreover, Bayne and Ross (2007) consider that there is a paradox at the centre of this debate because each person is fixed by his or her generational positionyou either are or you are not a "native." This fact has important consequences because it introduces a difficult perspective in terms of professional development. Older teachers and academic staff will never be able to bridge the gap arising from their generational position (Bayne \& Ross, 2007).

Most of the empirical evidence demonstrates that the situation is not so simple and that it is not obvious that such a digital generation actually exists in a homogenous way. There may be age-related differences concerning perceptions and experiences of technology-mediated learning, but there may also be other demographic characteristics, such as gender (Selwyn, 2008) and academic discipline (Kennedy, Judd, Churchward, Gray, \& Krause, 2008).

Empirical studies about the digital generation approach are mainly focused on the analysis of access to technology, the different types of use, and the transfer of technological skills to learning. Beyond these approaches, the initial hypothesis of this research is that the use of technology to support learning is not related to whether a student belongs to the Net Generation. It depends, rather, on the pedagogical and teaching models of the institution. Our study focuses on the analysis of ICT uses in academic contexts, comparing students at an online university versus students at traditional universities. 


\section{Technology Access and Uses}

Kennedy et al. (2008) found that there was significant diversity among first-year Australian students' use of technologies. Access, use, and preference varied considerably among students and degree programmes. The results of this research call into question the assumptions that underpin the idea of digital natives and the Net Generation. In the UK, Margaryan and Littlejohn (2008) found that students used a limited range of established technologies for learning, personal, and social use. They found that the youngest students were not used to advanced technologies and services, such as virtual worlds and personal web publishing. Furthermore, there was no evidence to support the idea that students were adopting radically different study patterns. Selwyn (2008) considered that we could not talk about a homogenous new generation of learners on the basis of a survey of UK students. There are important variations across age, gender, and socioeconomic status. Caruso and Kvavik (2005) found that students were comfortable with a core set of technologies but that they were less comfortable with specialised technologies.

\section{Transfer}

The main argument supporting the Net Generation discourse is that through frequent use of technologies, students become competent users, which makes them capable of transferring their digital skills to learning with the support of technology. However, most studies suggest that although today's students come to university with some digital skills, the use of digital media for studying might be quite different and the transfer of these skills is not automatic (Bullen, Morgan, \& Qayyum, 2011; Romero, Guitert, Bullen, \& Morgan, 2011; Kennedy et al., 2008; Kirkwood \& Price, 2005). Moreover, some characteristics, such as these students' ability to simultaneously process multiple channels of information, can have negative effects. For example, assuming that Facebook is something that students use concurrently with studying or other activities, Kirschner and Karpinski (2010) found a significant negative relationship between the use of Facebook and academic performance.

Kirkwood and Price (2005) argue that few students have high levels of competence across a wide range of applications and that familiarity with the use of email does not imply expertise in rigorous online debate and discussion (Kirkwood \& Price, 2005: 271). Margaryan and Littlejohn (2008) state that

for learning, mainly established ICTs are institutional VLEs [Virtual Learning Environment], Google and Wikipedia, and mobile phones... [The] findings point to a low level of use of and familiarity with collaborative knowledge creation tools, virtual worlds, personal web publishing, and other emergent social technologies. (p. 1)

Helsper and Eynon (2009) analysed the different aspects of what a digital native is by exploring whether it is determined by age, experience, or breadth of use. The conclusion was that the degree of digital expertise is related to confidence in the use of technologies, the use of the Internet as a first port of call for information, and the use of the Internet for learning, as well as other activities (Helsper \& Eynon, 2009, p. 9). 
The main findings suggest that communication and social activities are supported by the use of technology in daily life, while there are significant differences in the use of technology for learning. Along this line, Kennedy et al. (2008) have established an interesting distinction between "living" and "learning" technologies. Living technologies are those that people choose to use in their everyday life, mainly for social and leisure purposes. On the other hand, learning technologies are those that students use for intellectual or study purposes.

To summarise, young people have extensive access to technology, but the use of technology to support learning is very heterogeneous. There are some who engage in a wide range of technology-based activities, including content creation and self-publishing, while others never participate in those activities.

Taking into account that the use of technology to support learning in higher education is becoming more and more relevant, the debate must go beyond the characteristics of the new generation and focus on what it means to be a learner in a digital environment.

According to Dabbagh (2007), online learners must be ready to share their work, interact within small and large groups in virtual settings, and collaborate on projects online.

Studies have found that not all students report the same quality of conceptions of learning (Prosser \& Trigwell, 1999; Ramsden, 2002) and that this has a strong influence on student behaviour. In this direction, Jones, Ramanau, Cross, and Healing (2010) demonstrate that students are active users of technology but that they seem to respond to the requirements of their local course, programme, and university contexts.

\section{Aims and Methodology}

This article aims to clarify issues relating to the types of activities that technologies support in everyday and academic life for younger and older students. In this study, most of the younger students attend face-to-face universities, while the older learners attend an online university. The initial hypothesis is that the use of technology to support learning is not related to whether a student belongs to the Net Generation. It depends, rather, on the type of actions and tasks being carried out and is also influenced by the teaching model of the institution at which the learners are studying (online or face-to-face).

The main research questions of the study are as follows:

1. What are the differences between the use of "living" technologies and "learning" technologies by younger and older students?

2. What kinds of activities are supported by those technologies in everyday life and in academic life among younger and older students?

3. In which way does the university model affect learners in terms of ICT use and preferences?

To respond to these questions, we have analysed the results obtained from a questionnaire 
applied to a sample of students from five universities with different characteristics (one offers online education and four offer face-to-face education with LMS teaching-support) ${ }^{1}$. The participating students were selected using a set of criteria that would allow different profiles to be built. Thus, in this research, the independent variables considered are age, gender, education, employment activity, ICT equipment available, university institution of origin (educational model, virtual or face-to-face), course, and area of knowledge.

The dependent variables considered are as follows:

1. academic use of ICT (teacher-led): type, frequency of use, and perception of usefulness

2. academic use of ICT (decided by the students): type, frequency of use, and perception of usefulness

3. perception and evaluation of the use of ICT

The analysed population is the total number of students enrolled in their first or fourth year of study during the 2010-2011 academic year at Catalan universities. The final sample of participating students was a total of 1,042 people (error 5\%, confidence interval 95.5\%), and the selection was random.

The questionnaire is divided into two parts: the first part was developed with reference to a prior survey conducted by Kennedy, Judd, Churchward, Gray, and Krause (2008). The second part, based on a Likert-type scale, aims to analyse the students' perceptions of the use of ICT for learning.

To obtain a deeper analysis of the students' views, we conducted three focus groups. The main goal was to have a qualitative approach to the perception of the use of technology to support learning. A total of 17 students participated in the discussion. In each group, there were students from both the face-to-face and the online universities, and the ages varied: 11 students were between 19 and 25 years old, and 6 students were more than 26 years old.

In the following section, we present the results obtained from different types of analysis and from the focus groups. Firstly, we detail the main characteristics of the sample of students participating in the study. Secondly, we provide some general results regarding the use of technologies at the university, distinguishing between those suggested by teachers and those freely chosen by the students to help them carry out their academic work. Thirdly, using a segmentation analysis, we present the most characteristic and differentiating features of the two groups of students (face-to-face and online). Finally, we present an analysis focused on the students' attitudes and perceptions of the use of ICT in the university.

1 The online university is the Open University of Catalonia and the traditional/face-to-face universities are the University of Barcelona, the Polytechnic University of Catalonia, the Rovira and Virgili University, and the University of Lleida. 


\section{Results}

\section{Sample Characteristics}

Of the total 1,042 participants in the study, $36.9 \%$ are male and $63.1 \%$ are female. The knowledge areas in which they are carrying out their studies are social sciences (43.9\%), technical (25.6\%), humanities (25.7\%), and natural sciences (4.8\%). Of the total number of participants, $74 \%$ are in their first two years of study and $26 \%$ are between their third and fifth years. Almost half of them (45\%) also work.

In general, the level of access to technologies is high. The majority of the students typically connect to the Internet in their usual place of residence $(77.7 \%)$, followed by the family home (47.3\%), the workplace (36.9\%), and the university (30.9\%). The frequency of connection to the Internet is more than once a day in $82.9 \%$ of cases, and $13.5 \%$ connect just once a day. Only $3.6 \%$ connect to the Internet less frequently.

\section{Students' ICT Uses in Academic Activities}

In the questionnaire, students were asked about how they use ICT to carry out their academic work at the university. The questions distinguished between uses suggested by teachers as part of learning activities and those made on the students' own initiative.

If we look at the results shown in Charts 1 and 2, we can see that the uses perceived as most and least useful correspond fairly closely to those most and least often suggested by teachers. There is concordance between the students' perception of usefulness with regard to certain ICT resources and the teachers' suggested uses of technologies. Thus, we find that the most highly rated technologies (virtual campus [LMS], Internet searches, multimedia presentations, Google Docs, and YouTube) are also the most commonly recommended by teachers for carrying out academic work: virtual campus (98.2\%), Internet searches (96.5\%), multimedia presentations (81.7\%), YouTube (81.7\%), video/audio clips (76.7\%), Google Docs (69.7\%), wikis (68.1\%), forums (65.6\%), blogs (62.5\%), digital photography (6o.6\%), and social networks (59.8\%). 


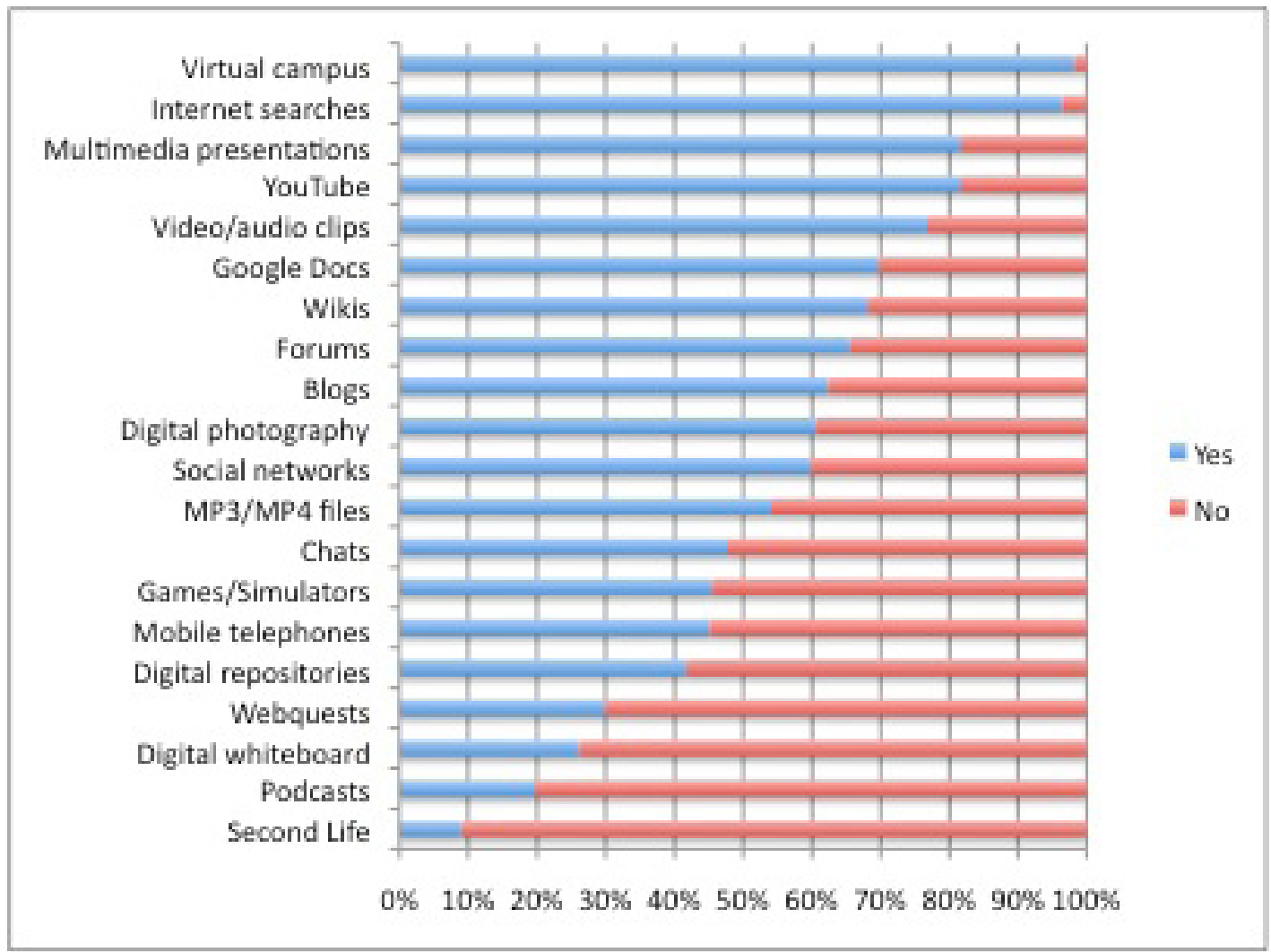

Chart 1. Teacher-led uses of ICT in academic tasks.

It is possible that the students are applying practical criteria when making their evaluation. Therefore, they consider that the most useful technologies are those that help them to better or more easily carry out the tasks set by teachers, and consider less useful, in contrast, those that do not adapt well to teachers' proposals. It remains to be determined whether the former are also the technologies that interest them most, motivate them, or genuinely help them to learn. 


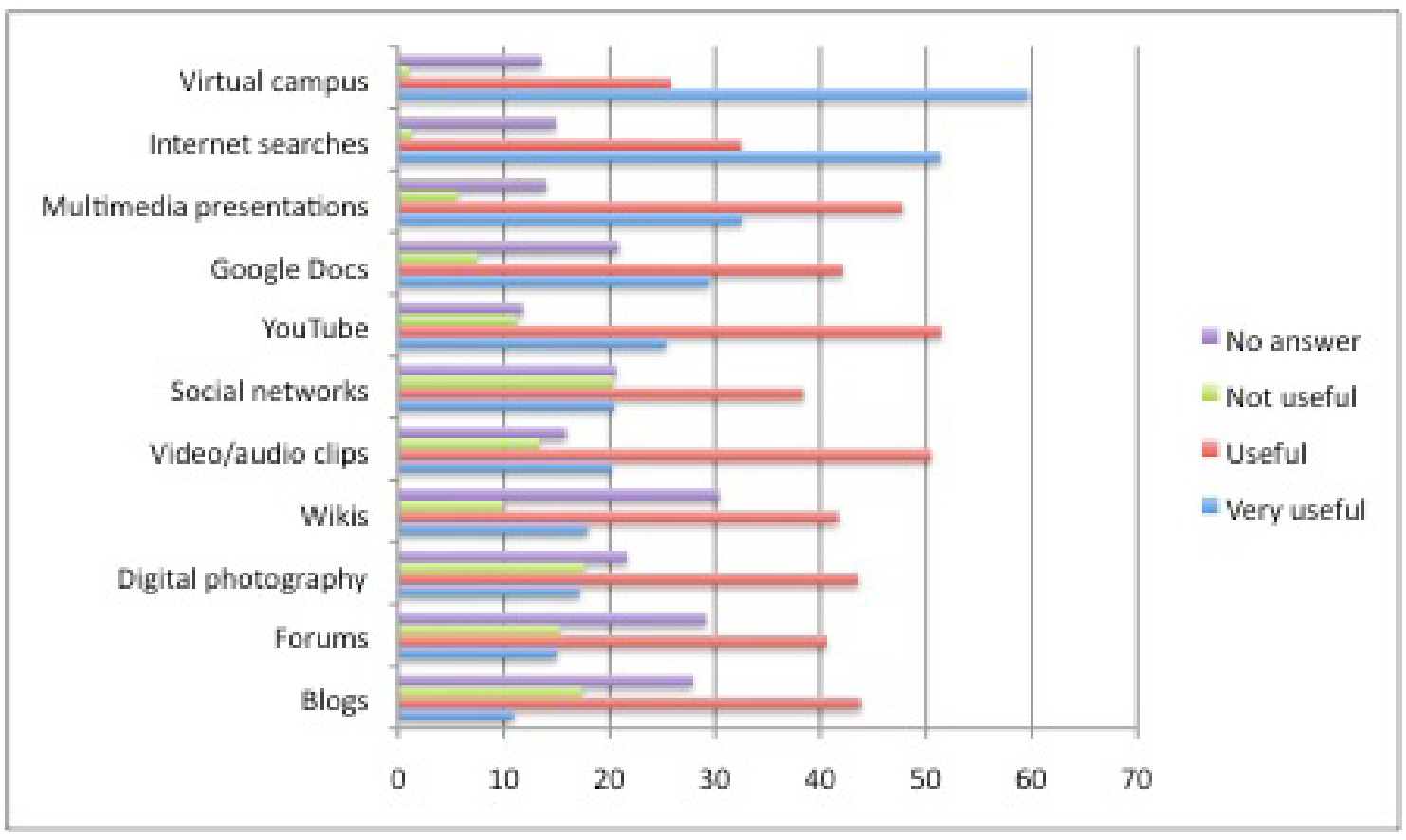

Chart 2. Uses perceived as most useful for carrying out academic tasks.

With regard to autonomous uses, the technologies and applications that the students use most frequently when carrying out academic tasks (Chart 3) continue to be the same and in very similar proportions: Internet searches (95.8\%) and virtual campus (91.2\%). In second position (with a frequency of between 60\% and 50\%), they mention YouTube, wikis, online documents (Google Docs), and multimedia presentations, almost all of them social networking tools. Between $45 \%$ and $30 \%$ mention social networks, blogs, audio and video clips, forums, and digital photography. Finally, the resources least used in a spontaneous fashion (by less than 10\% of the students) are Second Life, podcasts, webquests, digital whiteboards, games and simulators, and information repositories. In general, these are resources that are either more difficult for the students to access (as could be the case with Second Life or digital whiteboards) or that could require or be more directly associated with a specific teacher proposal guiding their use (webquests, games and simulators, etc.). In any case, we observe that podcasts and information repositories, which could in fact correspond to a more independent use by students, do not seem to meet their autonomous working needs, probably because their need to access information is covered by open searches on the Internet or by the documentation provided by teachers through the virtual campus. 


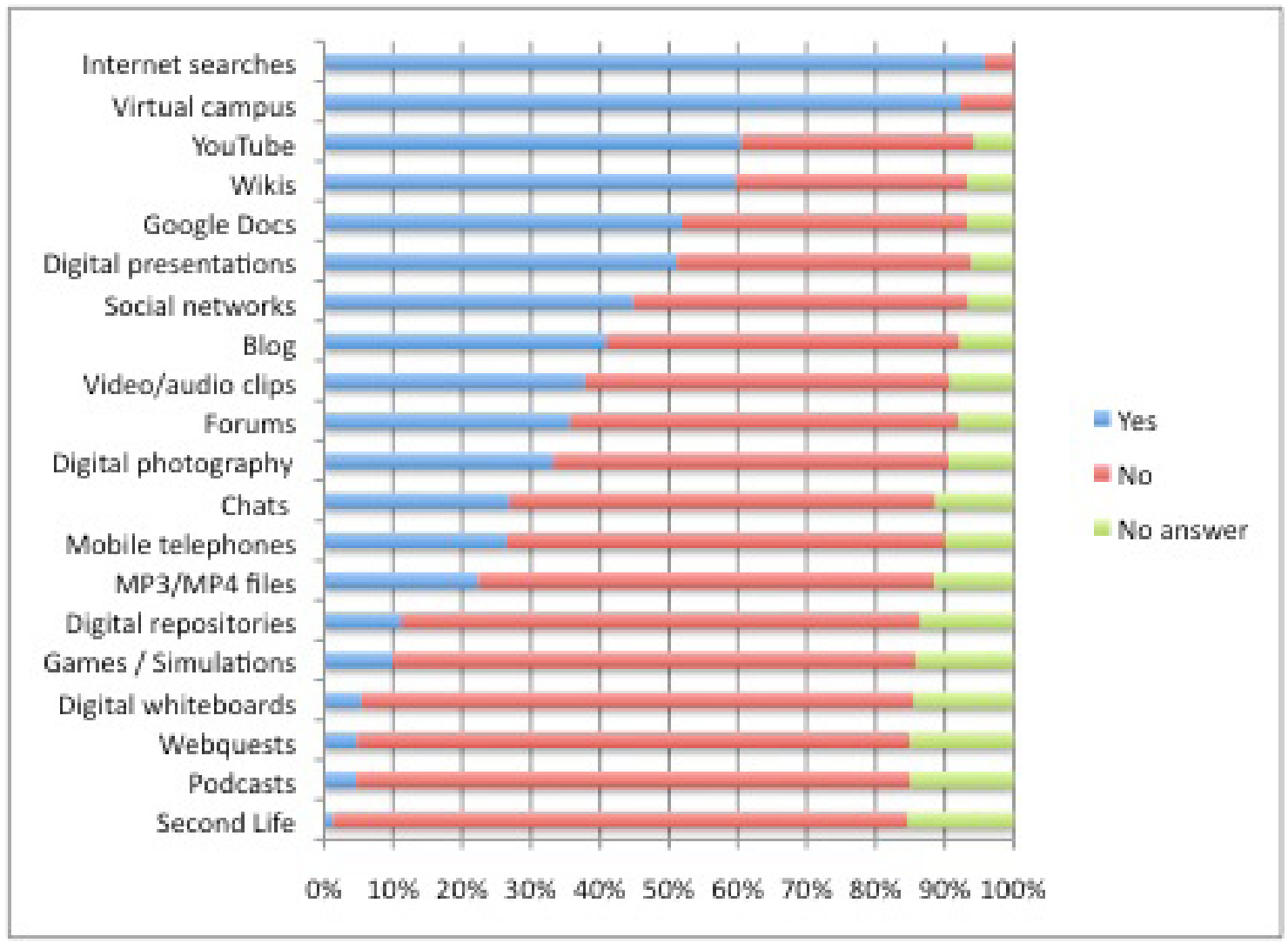

Chart 3. Autonomous uses of ICT in academic tasks.

In the focus groups, students described similar uses of ICT. Virtual campuses are mainly used to access provided readings, presentations, and general resources associated with the content of the course. There is not much interaction on the virtual campus in face-to-face universities. Technology instead tends to support traditional teaching methods:

Teachers are using PowerPoint as the main toolPowerPoint slides. You have to enter Moodle, download them, print them, and go to class with the slides, that's all. (student)

Some teachers read the PowerPoint slides and write long sentences. Too often the text is very long and no one reads it. I think they should prepare more visual lectures because people connect better with images, rather than with words that you cannot read. (student)

You have PowerPoint presentations in Moodle. For many students, this is the main content to study to the exam. Also, students are memorising things, and not seeking the information needed to go further on that subject. No, PowerPoint cannot be the most important tool. It can not be the only tool available.(student)

Some students complain that teachers assume they already have digital skills and therefore 
do not provide any specific support. This is different in the case of students in the online university because they have a compulsory course on digital skills during their first semester of studies.

In the university, people think that we know about ICT. They believe that we can use any kind of tool, but nobody teaches you. You have a digital blackboard and teachers don't know how to use it. This is incredible! I am lucky because I have worked for companies that used technology. In a company, you receive training because they know that you won't be efficient without these skills. But you come here and it is considered knowledge that you should already have, so no one teaches you. Maybe you are using resources very badly and inefficiently. (student)

Students are very critical about the way faculty use technology. In the discussion, we asked if they consider that social tools such as Facebook could be used to support formal activities. The answer was categorical: All students feel that they do not want to use Facebook for academic purposes; they want to establish a clear barrier between everyday life and learning.

Facebook, no, no... I will never accept a teacher on my

Facebook. (student)

Facebook, no. She is my teacher, not my friend. (student)

\section{Emerging Differences between Face-to-Face and Online Uni- versities}

Using a segmentation analysis, we present the most characteristic and differentiating features of the two groups of students studied, taking both the independent and dependent variables identified into account. Treating the information in this way allows us to detect the most characteristic of each group. We should highlight that what appears most associated with one group are not the characteristics presented by all of the components, nor are they the only ones. Instead, they are the characteristics that emerge as differentiating features of one group compared with the other in a statistically significant way (in this case, $p<$.001).

The informal use of ICT (i.e., use not connected to students' academic work) identified by each group is different (Table 1). The students at the virtual university use technologies for mainly informative and educational purposes, while among the students in face-to-face universities, the predominant use of technologies is for leisure and communication. 
Table 1

Informal Daily Use of ICT on Own Initiative

\begin{tabular}{|c|c|}
\hline Face-to-face mode & Online mode \\
\hline Use Internet to chat & Use Internet to send and receive email \\
\hline Use Internet to participate in a social network & Use Internet to access the virtual campus \\
\hline Use Internet to download software/films & $\begin{array}{l}\text { Use Internet to search for information for aca- } \\
\text { demic purposes }\end{array}$ \\
\hline Use Internet to listen to music & \\
\hline Use Internet to stay in contact with friends & Use Internet to search for general information \\
\hline Use Internet to make friends & Use Internet to access communication media \\
\hline Use Internet to share MP3 files & Use Internet to read content/ syndicated news \\
\hline Use a mobile telephone to listen to $\mathrm{MP}_{3}$ files & Use Internet to translate texts \\
\hline $\begin{array}{l}\text { Use a mobile telephone to take photographs or } \\
\text { videos }\end{array}$ & \\
\hline Use a mobile telephone to play games & \\
\hline Use a mobile telephone to make video calls & \\
\hline Use a computer to listen to music & \\
\hline Use a computer to play games & \\
\hline
\end{tabular}

With regard to the autonomous (i.e., not teacher-led) use of ICT that the students at one or other type of university exercise in their academic activities (Table 2), what stands out among the online students is fewer uses, which are more confined to the tools found in a virtual campus, while among the students in face-to-face universities, we see greater diversity in the use of technologies. This may be due to the diversity among the approaches used by the four face-to-face universities. 
Table 2

Uses of ICT in Academic Tasks

\begin{tabular}{|l|l|}
\hline Face-to-face mode & Online mode \\
\hline Social networks & Forums \\
Information repositories & Blogs \\
Mobile telephone & \\
YouTube & \\
Online documents (Google Docs) & \\
\hline
\end{tabular}

The perception of competence in the different uses of ICT is also different and coherent with the previously described uses (Table 3). Among the students in the virtual environment, we can see greater perceived competence in the use of most technologies, while among the students in face-to-face environments, there is a perception of having an average level of competence. Moreover, very different uses of technologies appear once again between both groups. 
Table 3

Competence in the Informal Use of ICT

\begin{tabular}{|c|c|}
\hline Face-to-face mode & Online mode \\
\hline $\begin{array}{l}\text { Average level of competence in using } \\
\text { the Intemet to } \\
\text { - translate texts } \\
\text { - send SMS } \\
\text { - publish photographs } \\
\text { - create a socisl network } \\
\text { - participate in a social network } \\
\text { - downlosd software } \\
\text { - resd content } \\
\text { - read blogs } \\
\text { - share MP3/MP4 files } \\
\text { - share photographs } \\
\text { - chat } \\
\text { - listen to music } \\
\text { - buy and sell } \\
\text { - make videoconference calls } \\
\text { - make telephone calls } \\
\text { - make friends } \\
\text { Average level of competence in using a } \\
\text { mobile telephone to } \\
\text { - listen to music } \\
\text { - make telephone calls } \\
\text { - take photographs } \\
\text { - send SMS } \\
\text { - play games } \\
\text { - organise } \\
\text { - make videos } \\
\text { Average level of competence in using a } \\
\text { computer to } \\
\text { - play games online } \\
\text { - create digital images } \\
\text { Average level of competence in using a }\end{array}$ & $\begin{array}{l}\text { High level of competence in using the } \\
\text { Intemet to } \\
\text { - access the virtual campus } \\
\text { - send and receive emsils } \\
\text { - search for information } \\
\text { - access communication media } \\
\text { - translate texts } \\
\text { - buy and sell } \\
\text { - read content } \\
\text { - make telephone calls } \\
\text { - make videoconference calls } \\
\text { High level of competence in using a } \\
\text { mobile telephone to } \\
\text { - take photographs } \\
\text { - send photographs } \\
\text { - make telephone calls } \\
\text { - reed blogs } \\
\text { - send SMS } \\
\text { - organise } \\
\text { - listen to music } \\
\text { High level of competence in using social } \\
\text { boolsmarking } \\
\text { High level of competence in using a } \\
\text { PDA as a personal organiser }\end{array}$ \\
\hline
\end{tabular}

Finally, with regard to students' use of ICT at their teachers' suggestion (Table 4), we see that the online students make more frequent use of a greater number of technologies, with a more clearly educational use and one associated with Web 2.0 than in the case of students in face-to-face environments. 
Table 4

Formal Use of ICT at Teachers' Suggestion

\begin{tabular}{|l|l|}
\hline Face-to-face mode & Online mode \\
\hline Frequently -virtual campus & Always -virtual campus \\
Always -mobile telephone & Always -repositories \\
Always -social networks & Always -forums \\
Always -MP3/MP4 files & Always -Google Docs \\
Always -YouTube & Always -Internet searches \\
& Always -wikis \\
& Always -blogs \\
\hline
\end{tabular}

Almost all the students participating in the focus groups use social networks to support their tasks and their study. They create their own groups independent of the "official" communication spaces in the virtual campus. Facebook seems to be the most popular.

We have created a group on Facebook. We have the official group in the [virtual] campus, but we use Facebook to work, to create open discussions and debates, etc.

I feel freer working in my Facebook group. Because I have comments to make, it helps to remind the calendar... We say, "Hey, this is for tomorrow!" It is not the official tool for the University.

I like WhatsApp because everyone has it, and you can talk quickly, and don't have to use the laptop. It is very useful to ask for information, you have many options for communication.

\section{Students' Perception of ICT Uses}

Finally, we present the results obtained regarding the students' perception of the use of technologies. To create the scale, we identified a set of indicators for each of the dimensions based on the domains of the didactic triangle: content, teaching, and social. However, instead of the traditional idea of content, we have identified indicators related not only to the content but also to the skills, similar to the cognitive dimension used in the CoI model (Garrison, Anderson, \& Archer, 2000). It is important to take into account that the items correspond to learning and teaching processes supported by technology in a broad sense, 
that is to say, either in virtual or blended environments, with different methodological approaches, and both led by teachers and decided by students. To analyse the reliability of the scale, Cronbach's alpha coefficient was applied, and the result was 0.944, which shows high reliability.

For uses included in the cognitive dimension, the level of agreement is higher among students at the online university in all cases except one ("ICT help me to do my academic homework better"). The perception of the usefulness of ICT from the cognitive perspective is therefore more positive among the online university students. This is detected in both those items that point to greater efficiency in obtaining learning results ("ICT help me to do my academic homework faster"; "I use ICT when I want to know more about a topic") and in those items more closely related to self-regulation and the perception of learning throughout the process ("ICT help me to follow the course"; "ICT facilitate my self-assessment processes").

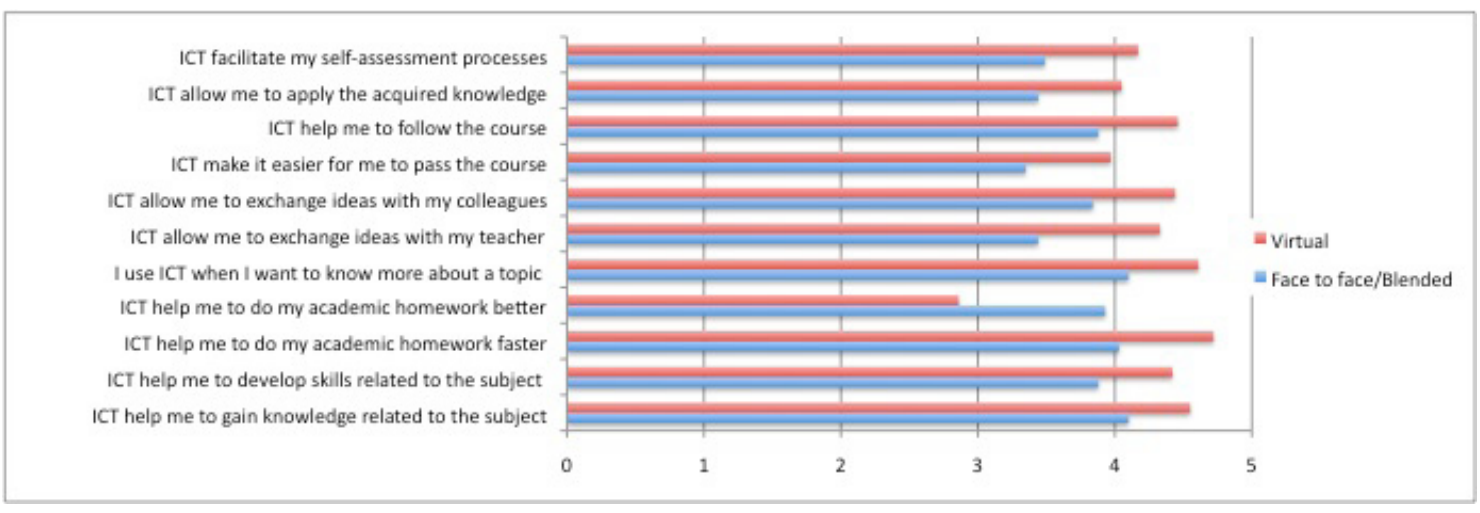

Chart 4. Cognitive dimension.

Chart 5 shows the results for the items related to the teaching dimension. The statements refer to the role of ICT in supporting the presentation of content, following the proposed methodology, and in detecting and resolving learning mistakes, whether through teaching use or not. In this case, the previous situation is repeated, thus the mean scores for use of technology by the students at the online university are higher in all cases. Of particular note, due to the high level of agreement between both groups, are those statements that refer to the presentation of content, the integration of knowledge from different sources, and the resolution of doubts by teachers.

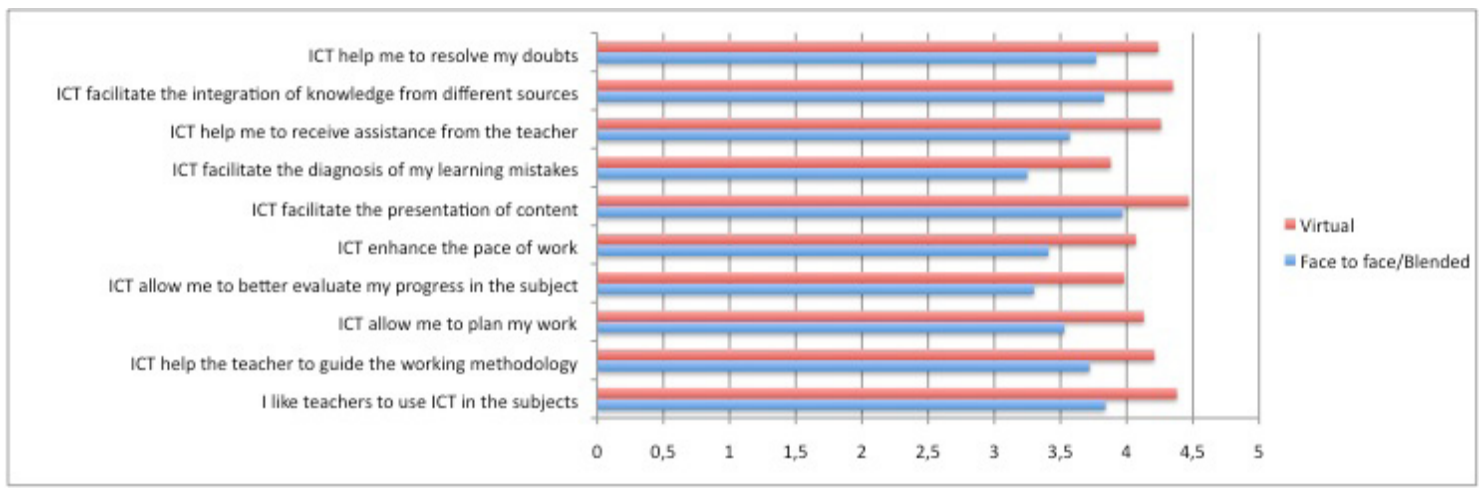

Chart 5. Teaching dimension. 
Finally (in Chart 6), we can see that the same situation is repeated again in relation to social presence. In this case, the statements refer to the use of technology for communicative purposes and to express the students' personality or emotions, and also the influence of technology on generating a positive atmosphere in the courses. We can see that the students at the online university expressed a higher level of agreement than the other group, in an even more pronounced way than in the previous dimensions. This is particularly noticeable in the statements that focus directly on communicative aspects ("ICT allow me to better communicate with my teacher"; "ICT help me to ask others questions") and on relationships and public projection of the students" work ("ICT allow me to publicly show what I do for the subjects").

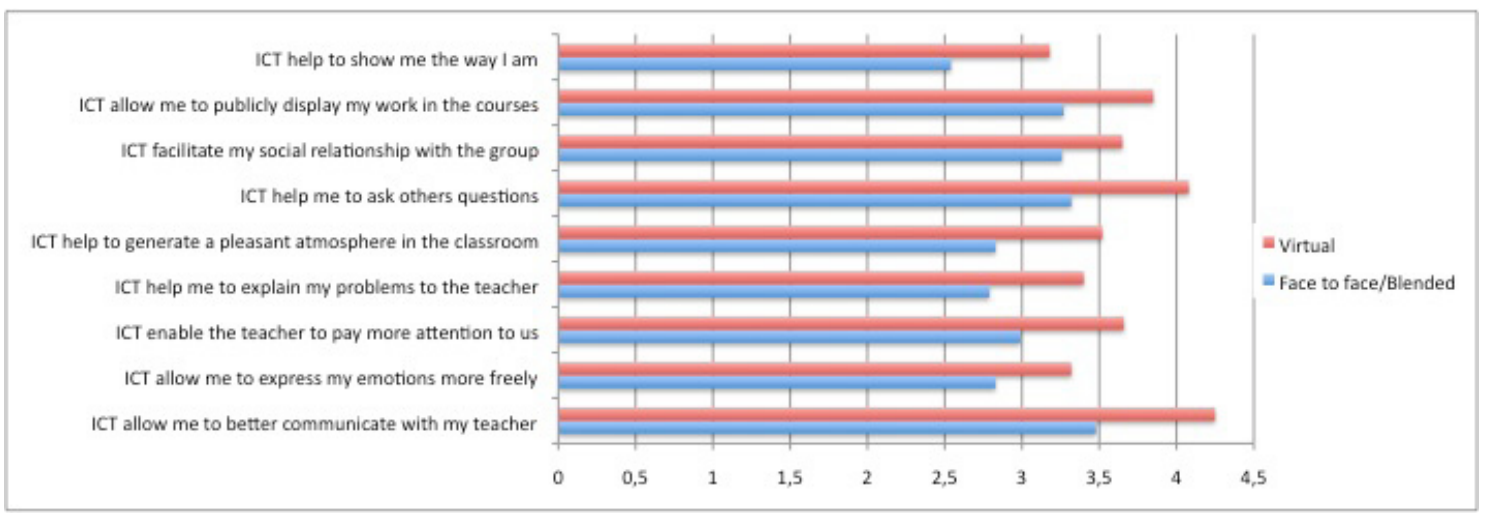

Chart 6. Social dimension.

If we compare the two groups of students in greater detail (Chart 7), the result obtained in percentages of agreement and disagreement in the case of the cognitive dimension becomes even more evident, clearly highlighting the gap between the groups for all levels of response.

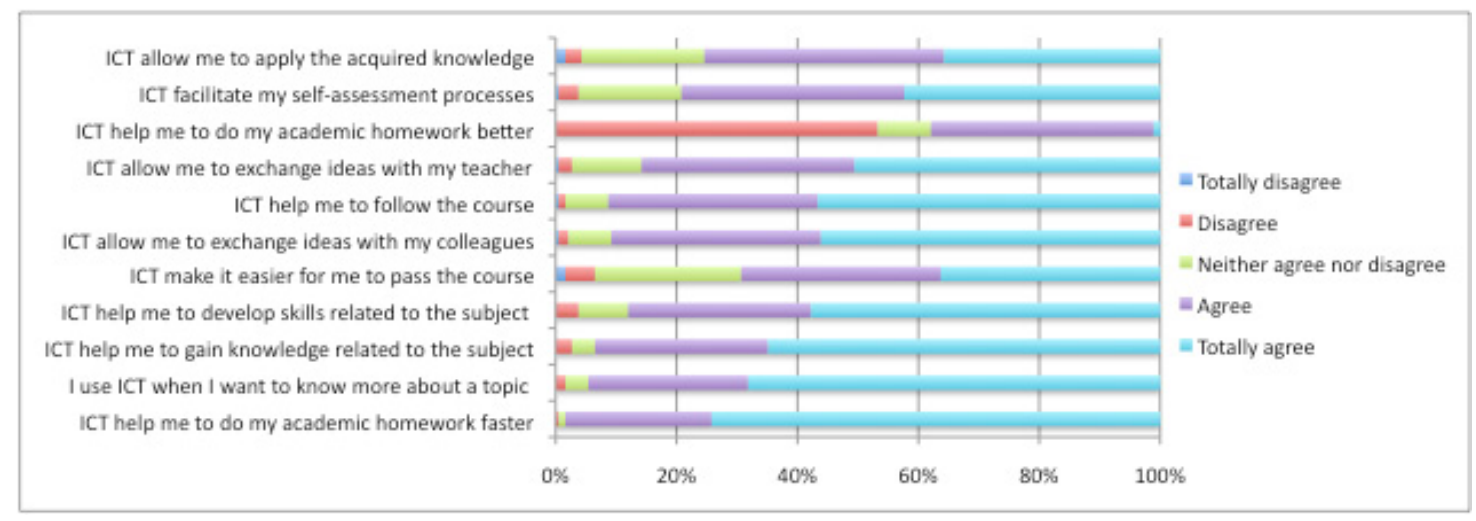

Chart 7. Cognitive dimension.

Chart 8 shows that the levels of disagreement and indifference are also higher in the group of students at face-to-face/blended universities. In the first case, these levels reach $10 \%$ of responses to some statements, and in the second case, they hit $40 \%$. 


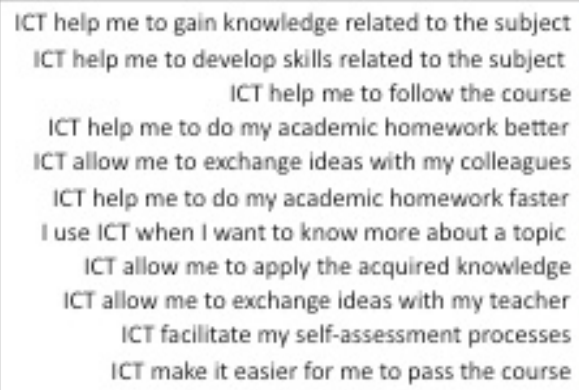

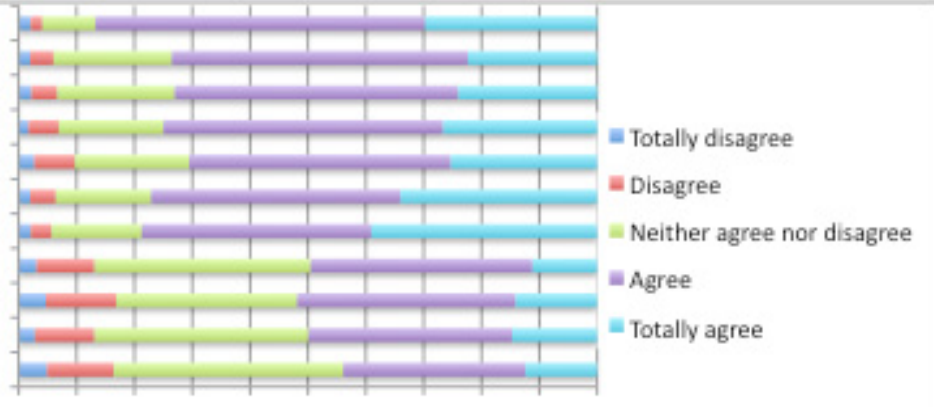

$0 \% 10 \% 20 \% 30 \%$ 40\% $50 \% \quad 60 \% \quad 70 \% \quad 80 \% \quad 90 \% 100 \%$

Chart 8. Content dimension.

In the case of the teaching dimension, this same gap can be clearly observed between the two charts (9 and 10), with some significantly higher proportions in the levels of agreement expressed by the online students, and lower in levels of disagreement.

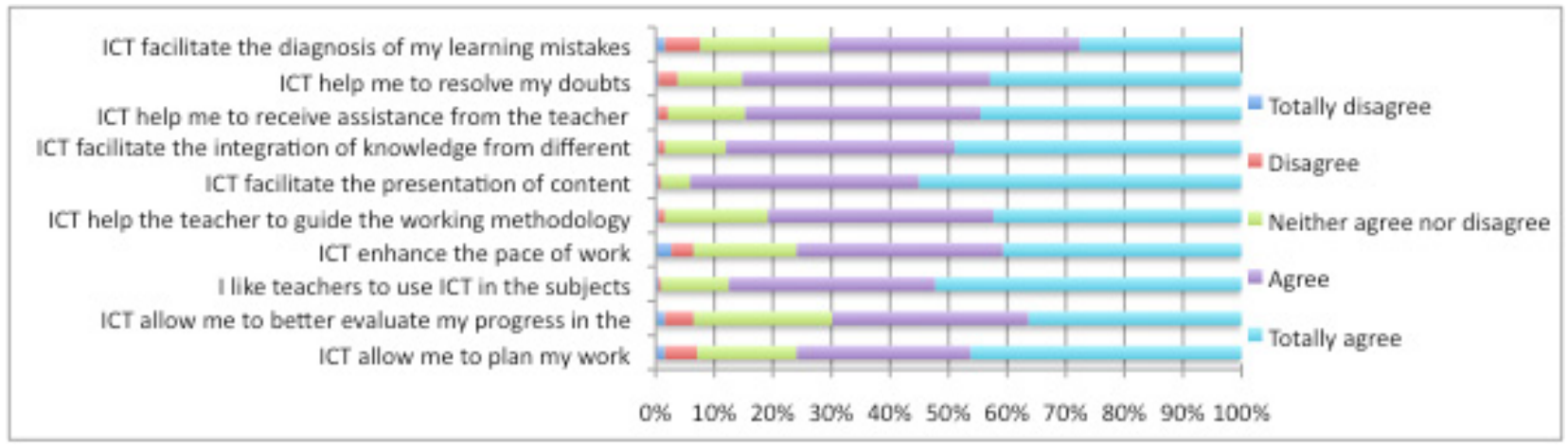

Chart 9. Perception of the use of ICT in virtual environments (teaching dimension)

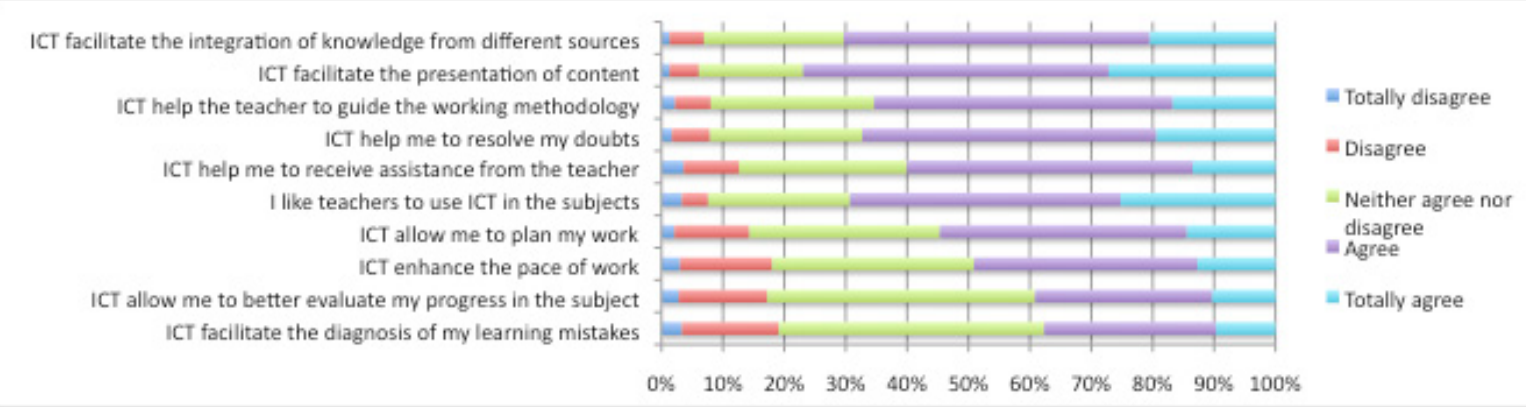

Chart 10. Perception of the use of ICT in face-to-face environments (teaching dimension)

\section{Discussion and Conclusions}

This research confirms many of the general points found in studies outside of Spain in relation to the level of technology access and use. The data obtained in this study shows that the university students in our sample have frequent and widespread access to technologies. They use technology on a daily basis, especially mobile telephones and some Internet applications. The conditions in terms of the availability and use of technologies are not different for younger and older students, and are quite generalised within the population 
entering the university. However, the use in everyday life is different. Young students are more active in communication and leisure activities, while older students are more focused on activities related to academic purposes.

Students perceive themselves as fairly competent in most areas (communication, creation, etc.), although the data does not indicate that these competences are necessarily reflected in the normal performance of academic tasks. Moreover, the results show important contradictions between the perception of technological proficiency and its use, which is much more restricted.

The students choose to use the Internet to search for information and they use their universities' virtual campuses as a gateway to the learning material for their courses. These findings are supported by previous research (Caruso \& Kvavik, 2005; Jones, Ramanau, Cross, \& Healing, 2010), which identify very habitual use of virtual campuses in traditional faceto-face universities.

General types of technology (computers, mobile telephones, and the Internet) are used for rapid communication and convenient access to services and information. If we look beyond these technologies and well-established tools, we find considerable variation in patterns of access, use, and preference for a wide range of different technologies. These results are similar to the findings in the work of Kennedy et al. (2008), and they contradict the key assumptions maintained by authors such as Prensky (2001) regarding the cognitive development of digital natives. It is becoming increasingly clear that although most university students have a basic set of technological abilities, these do not necessarily translate into sophisticated skills in the use of other technologies or information literacy in general.

Although access to and use of ICT is widespread, the influence of teaching methodology is very decisive. For academic purposes, students seem to respond to the requirements of their courses, programmes, and universities, as suggested by Brown and Czerniewicz (2008). In all cases, there is a clear relationship between the students' perception of usefulness regarding certain ICT resources and the teachers' suggested uses of technologies. The most highly rated technologies correspond with those proposed by teachers. In face-to face environments, the pedagogical model seems to be based on a traditional model in which the teacher provides the content and students value the use of ICT to present this content. In online environments, students perceived technology as supporting learning and communication. In this case, the value of ICT is not related to the content but to the learning process.

Greater use of technology for educational purposes also seems to condition the students' typical uses. Therefore, the students in virtual environments use technologies mainly for informative and educational purposes, while the students in face-to-face environments use ICT for leisure and communication. According to Margaryan and Littlejohn (2008, p. 4), a factor that may determine the types of tools students use and how they use them may be students' expectations of how they will learn at university. These authors investigated university entrants' expectations of how they would learn and what technologies they would be using at university over a four-year period. A key finding of this study is that despite a 
dramatic increase in students' use of various technologies, their expectations of how they might learn at university remained relatively static over the four-year period. The expectations of learning at university appear to be influenced more by students' prior experience of learning in formal situations rather than by their use of technology outside educational settings.

We can see important differences that are reflected not only in each dimension but also in the interrelations between them. The results obtained effectively demonstrate important differences in the three dimensions between the online students and those at the traditional universities. The perception of ICT use from the cognitive perspective is more positive among the students at the virtual university with respect to indicating greater efficiency in obtaining learning results, in aspects linked to self-regulation and the learning process. The social dimension is also higher in the online environment and is particularly interesting in the statements that refer directly to aspects of communication with teachers and relationships with colleagues. Nevertheless, it is interesting to note that the social dimension is valued lower than the other two by both groups of students. It remains to be determined if the reason is their minor interest in ICT social support during learning processes or the lack of adequacy of university virtual environments to bring support to social aspects.

The results of this study highlight differences between the students at face-to-face universities and at online universities, both in terms of technology usage and levels of perceived competence in these uses. The results have several implications. Firstly, it indicates that student-focused methods are possible in online teaching. The second implication follows from the first: the study indicates that teachers in face-to-face contexts need to focus not only on online materials, but also on how the use of ICT can support learning. This suggests that if teachers want students to get the most out of learning online in traditional contexts, then teaching strategies need to value the interaction with the teacher and the students. Online learning is not only part of the experience of students at a distance, it is an important aspect of campus-based student experiences.

Finally, the results of the study lead us to suggest the need to consider that technologyrich learning environments foster students' digital competencies (and not the other way around).

\section{Acknowledgements}

This article analyses the partial results of research funded by the Ministry of Science and Innovation, under the title Uses of ICT among university students: Academic and social perspective of the mediated learning processes (EDU2009-12125). 


\section{References}

Bayne, S., \& Ross, J. (2007). The "digital native" and "digital immigrant": A dangerous opposition. Paper presented at the annual conference of the Society for Research into Higher Education (SRHE), Brighton, Sussex, England.

Brown, C., \& Czerniewicz, L. (2008). Trends in student use of ICTs in higher education in South Africa. 10th Annual Conference of WWW Applications, Cape Town, South Africa. Retrieved from http://www.cet.uct.ac.za/files/file/ResearchOutput/2008 wwwApps UseTrends.pdf

Bullen, M., Morgan, T., \& Qayyum, A. (2011). Digital learners in higher education: Generation is not the issue. Canadian Journal of Learning \& Technology, 37(1).

Caruso, J. B., \& Kvavik, R. (2005). ECAR study of students and information technology, 2005: Convenience, connection, control, and learning. EDUCAUSE. Retrieved from http://net.educause.edu/ir/library/pdf/ers0506/rs/ers0506w.pdf

Dabbagh, N. (2007). The online learner: Characteristics and pedagogical implications. Contemporary Issues in Technology and Teacher Education, 7(3), 217-226.

Garrison, D. R., Anderson, T., \& Archer, W. (2001). Critical inquiry in a text-based environment: Computer conferencing in higher education. The Internet and Higher Education, 2(2-3), 87-105.

Helsper, E., \& Eynon, R. (2009). Digital natives: Where is the evidence? British Educational Research Journal, 36(3), 503-520.

Jones, C., Ramanau, R., Cross, S., \& Healing, G. (2010). Net Generation or digital natives: Is there a distinct new generation entering university? Computers and Education, 54(3), 722-732.

Kennedy, G., Judd, T. S., Churchward, A., Gray, K., \& Krause, K.-L. (2008). First year students' experiences with technology: Are they really digital natives? Australasian Journal of Educational Technology, 24(1), 108-122.

Kirkwood, A., \& Price, L. (2005). Learners and learning in the 21st century: What do we know about students' attitudes and experiences of ICT that will help us design courses? Studies in Higher Education, 30(3), 257-274.

Kirschner, P. A., \& Karpinski, A. C. (2010). Facebook® and academic performance. Computers in Human Behavior, 26(6), 1237-1245.

Margaryan, M., \& Littlejohn, A. (2008). Are digital natives a myth or reality?: Students' use of technologies for learning. Caledonian Academy, Glasgow Caledonian University, UK. Retrieved from http://www.academy.gcal.ac.uk/anoush/documents/ DigitalNativesMythOrReality-MargaryanAndLittlejohn-draft-111208.pdf 
Oblinger, D. G., \& Oblinger, J. L. (Eds.) (2005). Educating the Net Generation. EDUCAUSE. Retrieved from http://www.educause.edu/ir/library/pdf/pub7101.pdf

Prensky, M. (2001). Digital natives, digital immigrants. On the Horizon, 9(5), 1-6.

Prosser, M., \& Trigwell, K. (1999). Understanding learning and teaching: The experience in higher education. Buckingham: SRHE and Open University Press.

Ramsden, P. (2002). Learning to teach in higher education. London: Routledge.

Romero, M., Guitert, M., Bullen, M., \& Morgan, T. (2011). Learning in digital: An approach to digital learners in the UOC Scenario. European Journal of Open, Distance and E-Learning. Retrieved from http://www.eurodl.org/materials/special/2011/Romero_Bullen_Morgan.htm

Selwyn, N. (2008). An investigation of differences in undergraduates' academic use of the Internet. Active Learning in Higher Education, 9(1), 11-22.

Tapscott, D. (1998). Growing up digital: The rise of the Net Generation. Toronto: McGrawHill.

\section{Athabasca University $\mathbf{Z}$}

(c) () 